New Developments in Sheep Production

Occasional Publication No. 14-British Society of Animal Production 1990

edited by C. F. R. Slade and T. L. J. Lawrence

\title{
THE USE OF LIGHT AND MELATONIN TREATMENTS IN THE PREPARATION OF SUFFOLK RAMS FOR OUT-OF-SEASON BREEDING
}

\author{
H. LL. WILLIAMS, M. HANIF and G. CAIRNS
}

\begin{abstract}
Department of Veterinary Medicine and Animal Husbandry, Royal Veterinary College, Potters Bar EN6 INB
\end{abstract}
\section{INTRODUCTION}

$\mathbf{L}$ incoln and Davidson (1977) described the sequence of reproductive responses which occur in Soay rams following photostimulation. Several forms of photostimulation, involving a sequence of long and short days, are effective in modifying seasonal fluctuations in the reproductive parameters of rams (Jackson and Williams, 1973; Shanbacher, 1979). In ewes, photostimulation can initiate oestrous cycles during June/July and thus provide the opportunity for autumn lambing (Williams, 1977). Attempts to dispense with a priming period of 'long days' prior to the abrupt introduction of 'short days' were not successful for out-of-season breeding in Suffolk ewes (Williams and Ward, 1988). Conventional light treatments require controlled environment housing to provide 'long nights' and this has curtailed their widespread use, largely due to the cost of providing specialized housing and to the disruption of grazing management from April to June.

It has been established that melatonin is produced by the pineal gland only during the period of darkness and that it plays a key rôle in the periodicity of Soay rams (Almedia and Lincoln, 1984) and of Suffolk ewes (Arendt, Symons, Land and Pryde, 1983). Recent investigations have shown that melatonin treatment may replace the 'long night' phase of light treatments, and

TABLE 1

Treatments $\dagger$ and period

\section{February}

Group No. to 14 March

$\begin{array}{ll}\text { A } & 8 \\ \text { B } & 8 \\ \text { C } & 8 \\ \text { D } & 8\end{array}$

$18 \mathrm{~L}: 6 \mathrm{D}$

$18 \mathrm{~L}: 6 \mathrm{D}$

LL

LL
14 March to 9 September

$\mathrm{LL}+$ melatonin fed $\S$ $\mathrm{LL}+$ melatonin implant $\mathrm{LL}$
$L L+$ melatonin implant $\neq$

$\dagger \mathrm{LL}=$ local light at $51^{\circ} 43^{\prime} \mathrm{N} ; \mathrm{L}=$ hours of light; $\mathrm{D}=$ hours of dark.

$\ddagger$ Melatonin implant $=$ Regulin $^{\circledR} \quad($ Regulin Ltd, Australia).

$\S$ Melatonin $=M-5250$ (Sigma Chemical Company, USA). that a high level of fertility may be achieved in adult Suffolk ewes (Williams, 1984, 1985; Williams and Ward, 1988). It greatly simplifies the management of ewes bred out-of-season. Hanif and Williams (1988) have demonstrated that melatonin implants (Regulin ${ }^{\circledR}$, Regulin Ltd, Australia) are an effective alternative to 'long nights' in the treatment of yearling Suffolk rams for out-of-season breeding. The main objectives of this investigation were the comparison of timed and continuous (implant) administration of melatonin, and the evaluation of the rôle of a priming period of 'long days' preceding melatonin treatments applied to yearling Suffolk rams from mid March.

\section{MATERIAL AND METHODS}

Thirty-two yearling Suffolk rams were allocated to four treatment groups (A, B, C and D) on 1 February 1988. The treatments and their duration are shown in Table 1.

The rams were housed throughout the investigation and penned in subgroups of four rams. They were maintained on dried grass cubes, proprietary compound foodstuffs and mineral supplements according to recommended rates. Melatonin implants were inserted subcutaneously near the base of the ear at 5-week intervals.

Group B were group fed $100 \mathrm{~g}$ pelleted food per ram at $16.00 \mathrm{~h}$ daily. This provided approximately $3 \mathrm{mg}$ melatonin per ram. Testes measurements were made fortnightly. Sexual behaviour tests were carried out fortnightly; each ram was exposed to two treated ovariectomized ewes displaying oestrus for $10 \mathrm{~min}$, in a boarded test pen $100 \mathrm{~m}^{2}$. Quality assessments were carried out on semen samples, collected by artificial vagina, fortnightly. Semen collections and behavioural tests were undertaken during alternate weeks throughout the investigation.

\section{RESULTS}

\section{Live weight}

The main live weight of the four groups at three stages of the investigation are shown in Table 2 and show that there were no significant differences. 


\section{Testis diameter}

The mean testis diameter of each group, from the stage when significant differences were first recorded, is presented in Table 3 . There were no significant differences between groups $A$ and $B$ at any stage of the investigation. In groups $\mathrm{A}$ and $\mathrm{B}$ testis diameter increased until early July. Both groups were significantly higher than group D on nine consecutive occasions from 5 April to 26 July. Testis regression commenced in mid July in groups $\mathbf{A}$ and $\mathbf{B}$ and continued for the remainder of the investigation. In contrast, testis diameter in group $\mathrm{D}$ increased from mid June and was maintained for the remaining period; it was significantly higher than groups $A$ and B from 26 August onwards. In group C testis diameter slowly increased until the end of May, but remained significantly lower than groups A and B throughout May. In group C, testis regression occurred from mid June to mid July and was followed by another period of growth.

TABLE 2

Live weight $(\mathrm{kg})$

\begin{tabular}{|c|c|c|c|c|c|c|}
\hline \multirow[b]{3}{*}{ Group } & \multicolumn{6}{|c|}{ Date } \\
\hline & \multicolumn{2}{|c|}{27 January } & \multicolumn{2}{|c|}{14 June } & \multicolumn{2}{|c|}{9 September } \\
\hline & Mean & s.e. & Mean & s.e. & Mean & s.e. \\
\hline A & $56 \cdot 4$ & $2 \cdot 56$ & $71 \cdot 0$ & $2 \cdot 36$ & $81 \cdot 0$ & $2 \cdot 42$ \\
\hline B & $56 \cdot 1$ & $2 \cdot 58$ & $70 \cdot 4$ & $2 \cdot 34$ & $82 \cdot 0$ & $2 \cdot 08$ \\
\hline C & $57 \cdot 0$ & $3 \cdot 84$ & $69 \cdot 0$ & $3 \cdot 16$ & $81 \cdot 3$ & $3 \cdot 40$ \\
\hline D & $56 \cdot 1$ & $2 \cdot 47$ & $71 \cdot 3$ & $1 \cdot 39$ & $80 \cdot 5$ & $1 \cdot 41$ \\
\hline
\end{tabular}

\section{Sexual behaviour}

The mean number of services achieved per test period from the stage when significant differences occurred is shown in Table 4. Groups $A$ and B achieved higher numbers of services than group $D$ on 11 and 10 consecutive occasions respectively, and were also higher than group $\mathrm{C}$ on nine occasions. The performance of group D improved as the breeding season approached.

\section{Semen volume}

Table 5 shows the period during which significant differences were recorded in semen volume. Groups A and B did not differ significantly at any stage. Group A produced more semen than groups $C$ and $D$ on six and four occasions respectively; group $\mathrm{B}$ produced more than these two groups on six and two occasions. The semen volume of group $\mathrm{D}$ increased during the approach to the breeding season.

\section{Sperm concentration}

Significant differences between groups in sperm concentration were recorded between 20 April and 6 September (Table 6). Groups A and B did not differ at any stage; both were higher than control group $D$ on eight consecutive occasions and were higher than group C on six occasions. Group $C$ were higher than group D on two occasions during mid April and early May but this was not maintained.

\section{DISCUSSION}

The gradual increase in live weight, maintained from the yearling to the 19 month stage, conformed to the expected growth and development for that period. All

TABLE 3

Testis diameter $(\mathrm{mm}) \dagger$

\begin{tabular}{|c|c|c|c|c|c|c|c|c|}
\hline \multirow[b]{2}{*}{ Date } & \multicolumn{2}{|c|}{ Group A } & \multicolumn{2}{|c|}{ Group B } & \multicolumn{2}{|c|}{ Group C } & \multicolumn{2}{|c|}{ Group D } \\
\hline & Mean & s.e. & Mean & s.e. & Mean & s.e. & Mean & s.e. \\
\hline 05.4 .88 & $53 \cdot 50^{\mathrm{c}}$ & 1.38 & $52 \cdot 37^{b}$ & 1.68 & $51 \cdot 50^{\mathrm{a}}$ & $1 \cdot 38$ & $47 \cdot 00^{\mathrm{abc}}$ & 0.82 \\
\hline 19.4 .88 & $56 \cdot 0^{\mathrm{g}}$ & $1 \cdot 18$ & $56 \cdot 0^{\mathrm{h}}$ & 1.40 & $53 \cdot 25^{d}$ & 1.45 & $46 \cdot 38^{\text {ghd }}$ & 0.58 \\
\hline 03.5 .88 & $59 \cdot 63^{\mathrm{fb}}$ & $1 \cdot 54$ & $59 \cdot 0^{\mathrm{ga}}$ & $1 \cdot 12$ & $54.75^{\text {abh }}$ & 1.26 & $45 \cdot 88^{\mathrm{fgh}}$ & $0 \cdot 84$ \\
\hline 17.5 .88 & $60 \cdot 25^{\mathrm{fb}}$ & $1 \cdot 60$ & $62 \cdot 50^{\mathrm{gc}}$ & 1.35 & $56 \cdot 13^{\mathrm{bch}}$ & 1.25 & $47 \cdot 75^{\mathrm{fgh}}$ & 0.68 \\
\hline 31.5 .88 & $61 \cdot 13^{\mathrm{tb}}$ & 1.58 & $63 \cdot 25^{\mathrm{gc}}$ & 1.39 & $56 \cdot 50^{\mathrm{bch}}$ & $1 \cdot 30$ & $45 \cdot 38^{\mathrm{fgh}}$ & 0.55 \\
\hline 14.6 .88 & $62 \cdot 0^{f c}$ & 1.56 & $63 \cdot 50^{\mathrm{g}}$ & 1.24 & $56 \cdot 0^{\mathrm{gc}}$ & 1.07 & $45 \cdot 0^{\mathrm{fg}}$ & 0.66 \\
\hline 01.7 .88 & $63 \cdot 50^{8}$ & $1 \cdot 24$ & $65 \cdot 01^{\mathrm{h}}$ & $1 \cdot 10$ & $54 \cdot 50^{\mathrm{gh}}$ & 1.38 & $47 \cdot 0^{\mathrm{gh}}$ & 0.66 \\
\hline 14.7 .88 & $62 \cdot 0^{\mathrm{fc}}$ & 1.56 & $63 \cdot 0^{\mathrm{gh}}$ & $1 \cdot 10$ & $53 \cdot 0^{\mathrm{hc}}$ & 1.63 & $51 \cdot 0^{\mathrm{fg}}$ & 0.85 \\
\hline $26 \cdot 7 \cdot 88$ & $60 \cdot 0^{\mathrm{bc}}$ & $1 \cdot 56$ & $61 \cdot 0^{\mathrm{df}}$ & $1 \cdot 10$ & $54 \cdot 25^{\text {bd }}$ & 1.66 & $55 \cdot 0^{\text {cf }}$ & 0.73 \\
\hline 09.8 .88 & $58 \cdot 50$ & $1 \cdot 30$ & $59 \cdot 00$ & $1 \cdot 10$ & $56 \cdot 0$ & 1.70 & 57.00 & 0.73 \\
\hline 26.8 .88 & $50 \cdot 0^{\mathrm{b}}$ & $1 \cdot 35$ & $55 \cdot 0^{c}$ & 1.07 & $58 \cdot 0$ & 1.44 & $60 \cdot 0^{\mathrm{bc}}$ & 0.82 \\
\hline 09.9 .88 & $54 \cdot 0^{\mathrm{fb}}$ & 1.35 & $53 \cdot 0^{\mathrm{gc}}$ & 1.07 & $59 \cdot 0^{\mathrm{bc}}$ & 1.35 & $62 \cdot 0^{\mathrm{fg}}$ & 0.82 \\
\hline
\end{tabular}

$\dagger$ Values with similar superscripts within lines are significantly different: $a, b=$ $P<0.05 ; \mathrm{c}, \mathrm{d}=P<0.01 ; \mathrm{f}, \mathrm{g}, \mathrm{h}=P<0.001$. 
TABLE 4

Number of services per test period $\dagger$

\begin{tabular}{|c|c|c|c|c|c|c|c|c|}
\hline \multirow[b]{2}{*}{ Date } & \multicolumn{2}{|c|}{ Group A } & \multicolumn{2}{|c|}{ Group B } & \multicolumn{2}{|c|}{ Group C } & \multicolumn{2}{|c|}{ Group D } \\
\hline & Mean & s.e. & Mean & s.e. & Mean & s.e. & Mean & s.e. \\
\hline 13.4 .8 & $2 \cdot 7$ & 0. & $2 \cdot 57^{\mathrm{d}}$ & j & 2. & 8 & $2 \cdot 0^{\mathrm{ac}}$ & $0 \cdot 0$ \\
\hline & 2 & 0 . & $2 \cdot 67^{\mathrm{a}}$ & 0.21 & $2 \cdot 38$ & $0 \cdot 18$ & $1 \cdot 88^{\mathrm{ac}}$ & 0.23 \\
\hline 11.5 .88 & $2 \cdot 83^{\mathrm{fb}}$ & $0-17$ & $2 \cdot 83^{a g}$ & $0 \cdot 17$ & $2 \cdot 25^{\mathrm{ab}}$ & $0 \cdot 16$ & $1 \cdot 88^{\mathrm{fg}}$ & $0 \cdot 13$ \\
\hline 25.5 .88 & $2 \cdot 86^{a c}$ & $0 \cdot 26$ & $2 \cdot 67^{\mathrm{bd}}$ & $0 \cdot 21$ & $2 \cdot 0^{\mathrm{ab}}$ & $0 \cdot 19$ & $1.50^{\mathrm{cd}}$ & $0 \cdot 27$ \\
\hline 08.6 . & $2 \cdot 8$ & 0 . & $2 \cdot 67^{\text {bd }}$ & 0.21 & $1 \cdot 88^{\mathrm{eb}}$ & $0 \cdot 13$ & $1 \cdot 63^{\mathrm{cd}}$ & 0.18 \\
\hline 22.6 . & $3 \cdot 14$ & 0.26 & $2 \cdot 86^{a b}$ & 0.34 & $1.75^{\mathrm{gb}}$ & $0 \cdot 16$ & $1.71^{\text {ha }}$ & $0 \cdot 18$ \\
\hline 06.7 .88 & $3 \cdot 29^{\mathrm{ac}}$ & $0 \cdot 18$ & $2 \cdot 86^{\text {bd }}$ & $0 \cdot 14$ & $2 \cdot 0^{\mathrm{ab}}$ & $0 \cdot 38$ & $2 \cdot 0^{\text {cd }}$ & 0.27 \\
\hline 20.7 .88 & $3 \cdot 29^{\text {cd }}$ & $0 \cdot 18$ & $3 \cdot 0^{\mathrm{ab}}$ & 0.26 & $2 \cdot 25^{\text {bd }}$ & $0 \cdot 16$ & $2 \cdot 0^{\mathrm{ac}}$ & 0.19 \\
\hline 03.8 .88 & $3 \cdot 57^{\mathrm{cn}}$ & 0.20 & $3 \cdot 25^{\mathrm{de}}$ & $0 \cdot 16$ & $2 \cdot 13^{e n}$ & $0 \cdot 30$ & $2 \cdot 13^{\text {cd }}$ & 0.30 \\
\hline 17.8 .88 & $4 \cdot 0^{\mathrm{gh}}$ & $0 \cdot 22$ & $3 \cdot 50^{\mathrm{cd}}$ & $0 \cdot 27$ & $1.75^{\mathrm{hc}}$ & 0.37 & $2 \cdot 29^{\mathrm{gd}^{\mathrm{d}}}$ & 0.29 \\
\hline $31 \cdot 8.88$ & $3 \cdot 50^{\mathrm{gd}}$ & $0 \cdot 19$ & $3 \cdot 0^{\mathrm{h}}$ & $0 \cdot 19$ & $1.50^{\mathrm{ghc}}$ & 0.27 & $2 \cdot 57^{\mathrm{cd}}$ & 0.20 \\
\hline
\end{tabular}

$\dagger$ Values with similar superscripts within lines are significantly different: $\mathbf{a}, \mathbf{b}=$ $P<0.05 ; \mathrm{c}, \mathrm{d}, \mathrm{e}, \mathrm{n}=P<0.01 ; \mathrm{f}, \mathrm{g}, \mathrm{h}=P<0.001$.

TABLE 5

Semen volume $(m l) \dagger$

\begin{tabular}{|c|c|c|c|c|c|c|c|c|}
\hline \multirow[b]{2}{*}{ Date } & \multicolumn{2}{|c|}{ Group A } & \multicolumn{2}{|c|}{ Group B } & \multicolumn{2}{|c|}{ Group C } & \multicolumn{2}{|c|}{ Group D } \\
\hline & Mea & s. & Te: & . & M & s.e. & Aean & s.e. \\
\hline 91.6 & $1 \cdot 5$ & & & & & & & \\
\hline 15.6. & & $0 \cdot$ & & & & $0 \cdot 03$ & & 0.04 \\
\hline 12.7 .88 & $1 \cdot 20^{\mathrm{ac}}$ & $0 \cdot 12$ & $1 \cdot 08^{\mathrm{d}}$ & 0.20 & $0 \cdot 60^{\text {cd }}$ & $0 \cdot 11$ & $0.75^{\mathrm{a}}$ & $0 \cdot 15$ \\
\hline 26.7 .88 & $1 \cdot 13^{\mathrm{a}}$ & $0 \cdot 13$ & $1 \cdot 11^{\mathrm{b}}$ & 0.21 & $0.63^{\mathrm{ab}}$ & 0.15 & $0 \cdot 80$ & $0 \cdot 12$ \\
\hline 23.8 .8 & $1 \cdot 20^{\mathrm{ao}}$ & $0 \cdot 12$ & $1 \cdot 15^{\mathrm{b}}$ & 0.15 & $0.63^{\mathrm{ab}}$ & $0 \cdot 16$ & $0.83^{\circ}$ & 0.09 \\
\hline 06.9 .88 & $1 \cdot 31^{\mathrm{c}}$ & $0 \cdot 19$ & $1.25^{\mathrm{b}}$ & 0.22 & $0.61^{\mathrm{abc}}$ & 0.07 & $1.20^{\mathrm{a}}$ & $0 \cdot 16$ \\
\hline
\end{tabular}

$\dagger$ Values with similar superscripts within lines are significantly different: $a, b$, $\mathrm{o}=\mathrm{P}<0.05 ; \mathrm{c}, \mathrm{d}=P<0.01 ; \mathrm{f}=P<0.001$.

TABLE 6

Sperm concentration $\left(\times 10^{9} / \mathrm{ml}\right) \dagger$

\begin{tabular}{|c|c|c|c|c|c|c|c|c|}
\hline \multirow[b]{2}{*}{ Date } & \multicolumn{2}{|c|}{ Group A } & \multicolumn{2}{|c|}{ Group B } & \multicolumn{2}{|c|}{ Group C } & \multicolumn{2}{|c|}{ Group D } \\
\hline & Mea & s.e. & M & s.e. & Mean & s.e. & Mean & s.e. \\
\hline 4 & $4 \cdot 12$ & 0 . & 4 & 7 & 4. & $0 \cdot 12$ & & 0.04 \\
\hline 15 & & & & & $4 \cdot 6$ & & & 0.1 \\
\hline & & & & & 4. & & & 0. \\
\hline 01. & & & & & 3 . & & 3.4 & \\
\hline 15.6 . & & 0. & & 0 & $3 \cdot 6$ & 7 & $3 \cdot 5$ & ). 0 \\
\hline 12.7 .8 & 4.9 & 0 & & 0.2 & $3 \cdot 5$ & 0.38 & $3 \cdot 60^{\mathrm{en}}$ & 0.26 \\
\hline 26.7 .88 & $4 \cdot 86^{\mathrm{ac}}$ & $0 \cdot 21$ & $4.72^{\text {bd }}$ & $0 \cdot 26$ & $3 \cdot 35^{\text {cd }}$ & 0.27 & $3.67^{\mathrm{ab}}$ & $0 \cdot 34$ \\
\hline 23.8 .88 & $4 \cdot 56^{\mathrm{ce}}$ & $0 \cdot 15$ & $4 \cdot 42^{\mathrm{dn}}$ & $0 \cdot 18$ & $3 \cdot 54^{\text {cd }}$ & 0.34 & $3 \cdot 70^{\mathrm{en}}$ & 0.21 \\
\hline 06.9 .88 & $4 \cdot 32^{c}$ & $0 \cdot 15$ & $4 \cdot 20^{\mathrm{d}}$ & $0 \cdot 19$ & $2.93^{\mathrm{acd}}$ & 0.27 & $4 \cdot 0^{\mathrm{a}}$ & 0.19 \\
\hline
\end{tabular}

$\dagger$ Values with similar superscripts within lines are significantly different: $a, b$, $\mathrm{o}=\mathrm{P}<0.05 ; \mathrm{c}, \mathrm{d}, \mathrm{e}, \mathrm{n}=P<0.01 ; \mathrm{f}, \mathrm{g}, \mathrm{h}=P<0.001$. 
rams remained in good health throughout the investigation.

It is evident from the data on testis size, sexual behaviour and semen quality, that treatments $\mathrm{A}$ and $\mathrm{B}$ resulted in a significant advancement in reproductive performance. Timed and continuous administration of melatonin preceded by a priming period of long days, were equally effective in this respect. The advancement achieved in both groups was comparable with that recorded in yearling Suffolk rams in response to photostimulation $(18 \mathrm{~L}: 6 \mathrm{D} ; 9 \mathrm{~L}: 15 \mathrm{D})$ and to 'long days) (18L : 6D) followed by melatonin implants (Hanif and Williams, 1988). The uniform responses observed as a result of these treatments reflect the subtle changes which occur at the hypothalamic level and demonstrates the efficacy of melatonin treatments for the preparation of rams for out-of-season breeding.

A full assessment of fertility was outside the scope of this investigation but the criteria of assessment included those which are commonly used to assess rams in artificial insemination studies (Evans and Maxwell, 1986). The advancement of high reproductive performance in rams is comparable with that achieved in Suffolk ewes on similar forms of treatment (Williams, 1985; Williams and Ward, 1988). In terms of reproductive management, the availability of both cyclic ewes and high performance rams during June/July is advantageous for it allows the application of procedures normally practised in autumn tupping flocks. Since winter housing is now prevalent in many areas the 'long days' associated with treatments $A$ and $B$ can be readily applied; the subsequent use of melatonin implants requires no change in conventional management after the ewes are turned out to grass.

The failure of treatments A and B to sustain high reproductive performance beyond early July is in keeping with the observations of Almedia and Lincoln (1984) who showed that rams become refractory after 16 to 20 weeks of exposure to a specific light regime. It is clear from these data that this phenomenon also applies to melatonin treatments. The data indicate that rams treated in this way may not be at peak performance during the following autumn.

There are situations where it may be difficult to apply the priming period of long days. The data for group $\mathrm{C}$ indicate that the abrupt application of melatonin in mid March resulted in a weak response in terms of all the criteria of assessment. This suggests that the normal change in the light : dark ratio from the winter solstice to mid March is inadequate priming for treatment $\mathrm{C}$ and that the type of treatment is inappropriate in mid March. The same form of treatment applied from early April to adult and yearling Suffolk ewes resulted in low fertility (Williams and Ward, 1988). Further investigation is required on the use of melatonin treatments initiated between the spring equinox and the summer solstice.

\section{REFERENCES}

Almedia, O. F. X. and Lincoln, G. A. 1984. Reproductive photorefractoriness in rams and accompanying changes in the patterns of melatonin and prolactin secretion. Biology of Reproduction 30: 143-158.

Arendt, J., Symons, A. M., Land, C. A. and Pryde, S. J. 1983. Melatonin can induce early onset of the breeding season in ewes. Journal of Endocrinology 97: 395-400.

Evans, G. and Maxwell, W. M. C. 1986. Salamon's Artificial Insemination of Sheep and Goats. Butterworths, London.

Hanif, M. and Williams, H. LL. 1988. The effects of melatonin and light treatment on the reproductive performance of yearling Suffolk rams. Proceedings of the 11th International Congress on Animal Reproduction and Artificial Insemination, Dublin, Vol. IV, p. 578.

JACKSON, G. and Williams, H. Ll. 1973. The effect of imposed light rhythms on semen production of Suffolk rams. Journal of Agricultural Science, Cambridge 81: 179-188.

Lincoln, G. A. and Davidson, D. W. 1977. The relationship between sexual and aggressive behaviour and pituitary and testicular activity during the seasonal sexual cycle of rams, and the influence of the photoperiod. Journal of Reproduction and Fertility 49: 267-276.

SCHANBACHER, B. D. 1979. Increased lamb production with rams exposed to short daylengths during the non-breeding season. Journal of Animal Science 49: 927-932.

Williams, H. Ll. 1977. Environmental control of oestrus with particular attention to alterations of daylength. Proceedings of the 28th Annual Meeting of the European Association for Animal Production Brussels, Belgium, M-SG/5.04/1-6.

Williams, H. LL. 1984. The effect of feeding melatonin during late summer on the onset of the breeding season of sheep. British Veterinary Journal 140: 407-408.

WILLIAMS, H. LL. 1985. The use of melatonin to initiate breeding activity in photoperiodic breeds of sheep. Proceedings of the 36th Annual Meeting of the European Association for Animal Production Halkidiki, Greece.

Williams, H. Ll. and WARD, S. 1988. Melatonin and light treatment of ewes for autumn lambing. Reproduction, Nutrition, Développement 28: 7985 . 